\title{
LA JORNADA DE TRABAJO EN EL NUEVO RÉGIMEN DE TRABAJO AGRARIO
}

POR JUAN IGNACIO MANOCHIO ${ }^{1}$

Sumario: 1.-Introducción. 2.- Antecedentes normativos que regularon al trabajo agrario.3.- La ley 26.727. 4.- La ansiada jornada de 8 horas diarias. 5.-Conclusión.

\section{I.- Introducción}

Podría afirmarse que el trabajo rural es una de las manifestaciones más antiguas de labor humana. Su nacimiento se genera con la organización de comunidades primitivas y su adopción de hábitos sedentarios. Sus orígenes pueden rastrearse hasta los albores de la civilización y ostenta la peculiar característica de haberse desarrollado prácticamente en todo tiempo y lugar, pues se halla ligado a la satisfacción de las necesidades básicas y comunes de todos los hombres.

Siendo una actividad manual, ejecutada por sectores socialmente postergados, en la que la capacitación se adquiere prácticamente mediante la experiencia, y que no exige otro requisito para su ejecución que la voluntad, se puede decir que el trabajo agrario no ha sido valorado por la sociedad y, en definitiva, por el legislador como su legítimo representante, en la misma medida que otras actividades.

Entonces, es común la afirmación sobre "el olvido" del trabajador agrario por parte del legislador social y las razones que convergen en esta circunstancia son múltiples. Amén de lo afirmado precedentemente, sabido es que el nacimiento y expansión del Derecho del Trabajo está conectado indisolublemente con el fenómeno industrial que le presta su marco y desencadena la problemática cuestión obrera donde germinaron las nuevas direcciones del pensamiento jurídico, que desembocan en él y tiene el ámbito urbano como su escenario natural. Por todo ello, el ámbito del trabajo agrario tenía garantizado, lamentablemente, la exclusión de los derechos que gozaban la gran mayoría del resto de los trabajadores, y entre ellos, la implementación de la "famosa" jornada "de sol a sol" que data de la Edad Media, con el auge de la esclavitud, donde el "siervo" era un trabajador semiindependiente que tenía que trabajar para el señor feudal desde la salida del sol hasta la noche.

A pesar de estas circunstancias, no se puede dudar que existe y siempre existió un vínculo entrañable entre la historia argentina y el agro; unión que se refleja no sólo en la estructura económica del país y su consecuente configuración institucional y política, sino también en su profunda imbricación en el ámbito de las costumbres, los hábitos y las tradiciones más arraigadas de nuestro pueblo. No en vano, Argentina fue catalogada

1 Juan Ignacio Manochio es abogado(Universidad Siglo XXI de Córdoba), Especialista en Derecho Laboral(convenio UNC,UNL y UCC); investigador de la UBP de Córdoba; ejerce la profesión liberal de abogado y además es abogado fiscal en el Tribunal de Cuentas de la Provincia de Córdoba. 
durante muchos años como el "granero del mundo", denotando la importancia económica que significaba y significa dicho sector en la producción, exportación y rentas del país. Teniendo en cuenta la importancia del sector, es que a fines del 2011 el Congreso de la Nación (a propuesta del Poder Ejecutivo Nacional) resolvió derogar el jurídicamente vetusto Régimen Nacional del Trabajador Agrario (ley 22.248), entre las cuales una de las principales modificaciones fue la radical reducción de la jornada de trabajo del empleado rural.

\section{Antecedentes normativos que regularon al trabajo agrario}

Los trabajadores rurales, pese a la singular característica de que la economía del país dependiese de este sector productivo, prácticamente carecieron de derechos hasta el surgimiento del Constitucionalismo Social.

En primer lugar, encontramos los códigos rurales provinciales, con los cuales se inician las primeras reglamentaciones de trabajo agrario, inmediatamente posteriores a la organización nacional. Como ejemplo de estos códigos encontramos al de la Provincia de Buenos Aires, sancionado por la ley 469 de 1865, el cual consagró la clásica distinción que desembocaría en la moderna división entre trabajadores permanentes y temporarios. Bajo su influjo se dictan los de Santa Fe en 1867, Corrientes en 1871, Entre Ríos en 1873, Catamarca en 1878 y Mendoza en 1880. Sin embargo, a pesar del avance legislativo que significó dada la época (incluso antes de la sanción del Código Civil en 1871), dichas regulaciones eran en su gran mayoría escasas como así también vagas, no tendientes a regular la actividad agraria en sí, sino que buscaban básicamente atender a la solución de algunos problemas apremiantes y sobre todo a lograr el orden en la campaña mediante la inclusión de disposiciones de contenido puramente administrativo y policíaco.

Motivada por las críticas que provocaban las condiciones inhumanas de trabajo de los denominados "braceros", el 29 de septiembre de 1942 se dictó la ley 12.789, también Ilamada "Estatuto de los Conchabadores", la cual tuvo por objeto regular la actividad de intermediarios, o también llamados "negreros", quienes contrataban obreros rurales para destinarlos al trabajo en distintos predios. Esta norma estuvo destinada a regir una sola de las categorías de trabajadores rurales, la de aquellos que temporalmente abandonaban sus hogares, y se dedicaban a realizar tareas de "braceros" en actividades agrícolas, ganaderas, mineras, forestales, o de cualquier otra índole. No estaban comprendidos los cosecheros y tampoco los trabajadores permanentes.

Luego, con el surgimiento de nuevos protagonistas políticos a mediados de la década del 40, se alcanzó ahora sí una mínima tuición para una actividad laborativa que justificaba plenamente que se le prestara una atención diferenciada.

Es así que recién en 1944 se dicta la primera regulación orgánica para los trabajadores del agro. El decreto-ley 28.169/44 (luego convalidado por ley 12.921) y su reglamentación (decreto 34.147/49) conocidos como el "Estatuto del Peón Rural”, recogieron las necesidades normativas de ese sector de trabajadores completamente desprotegidos hasta entonces. Se trata de lo que denominamos hoy como trabajadores permanentes, esto es, los que integran la planta estable del establecimiento. Lo propio hizo la ley 13.020 del año 1947 para los trabajadores cosecheros (hoy no permanentes), y cuyo principal aporte fue la creación de la Comisión Nacional de Trabajo Rural (hoy Comisión Nacional de Trabajo Agrario o C.N.T.A.), organismo de composición tripartita 
que tenía a cargo la creación de resoluciones que regularan la actividad cíclica en el ámbito agrario. La misma reguló las condiciones de asistencia sanitaria, alimentación adecuada, vivienda higiénica, y horarios establecidos de antemano para el trabajador.

Aunque fue sancionada con carácter de norma de emergencia, la vigencia del Estatuto del Peón Rural, junto con la ley 13.020 de cosecheros, se extendió hasta 1980. El estatuto era una ley sumamente práctica que aportaba dos novedades de suma importancia: la primera fue la protección de la estabilidad en el empleo del trabajador rural castigando con una obligación indemnizatoria al principal que lo despidiera injustamente, y cuyo monto era la mitad de la retribución mensual por cada año de servicio, derecho que se abría al trabajador una vez completado un año de antigüedad en el empleo. La segunda novedad era el amparo de las enfermedades o accidentes ajenos al trabajo (es decir, inculpables) para lo cual se creaba el deber del empleador de abonar la mitad de la remuneración durante el período de inhabilitación.

Con la sanción de la Ley de Contrato de Trabajo 20.744 (en adelante L.C.T.), el 11 de septiembre de 1974, se cumplió el mandato constitucional introducido en 1957 por el artículo 14 bis de proteger el trabajo en todas sus formas.

Por su artículo $2^{\circ}$ se dispuso que en los casos de actividades regladas por estatutos, o regímenes particulares, serían aplicables las disposiciones de la ley, cuando las mismas contemplen situaciones no previstas en dichos estatutos o consagren beneficios superiores a los establecidos por ellos, considerándose en particular cada instituto del derecho del trabajo, quedando ello condicionado a que la aplicación de sus disposiciones resulte compatible con la naturaleza y modalidades de la actividad de que se trate, y con el específico régimen jurídico a que se halle sujeta.

El 23 de abril de 1976 mediante ley 21.297 se reforma la L.C.T. en el citado artículo 2ํㅡㄹ excluyendo la mención a los Estatutos Especiales.

El Estatuto del Peón Rural, que significó un verdadero cisma para la realidad socio-política de aquellos años, perduró hasta que en el cíclico devenir de las cambiantes condiciones políticas de ese período en nuestro país, a través de una dictadura cívicomilitar se impuso una nueva regulación, nacida esta vez de los sectores de la producción directamente involucrados.

El 27 de julio de 1980 se dicta la ley 22.248, que derogó, y reemplazó al régimen anterior, destacándose la exclusión del trabajador agrario al régimen de la L.C.T., mediante su artículo 3을 inso c).

De esta forma, la ley de facto 22.248 (de la época de Videla y Martínez de Hoz) vino a reemplazar al decreto-ley 28.169/44 (Estatuto del Peón Rural) y a la ley 13.020. El primero atrapaba al Ilamado, aún hoy, trabajador permanente, y la segunda ley, al no permanente, denominación ya desaparecida, pero no así sus supuestos normativos, que siguen siendo los mismos en el nuevo régimen de la actual ley 26.727. La ley 22.248 incluye en una sola regulación a ambos. En realidad constituye una fusión de aquellas otras normativas, al tiempo que, también una evolución legislativa, desde que más allá de las muchas y serias críticas que se le formularon a esta ley de facto, igualmente importó un avance normativo, una mejora en varios de los derechos de los trabajadores agrarios. 
Además de dicha fusión, y con la tácita finalidad de evitar cualquier vacío regulatorio en materia de trabajo no permanente, al presentarse ésta como una ley cerrada y autosuficiente, mantuvo la vigencia de las resoluciones vigentes en el momento de su sanción, tanto las dictadas por la ex Comisión Nacional de Trabajo Rural como por el Ministerio de Trabajo en ejercicio de las funciones conferidas a aquélla mientras no fueren especialmente modificadas.

En sus poco más de tres décadas de funcionamiento, la ley 22.248 se mostró, en general, como limitativa y en ciertos aspectos hasta discriminativa de los derechos del trabajador rural. Pretendió erigirse, como ya se dijo, como un estatuto autosuficiente, y por ende, aislado del resto de la legislación laboral.

Sin duda, factores propios del ámbito jurídico y tecnológico fueron llevando a la necesidad impostergable de una modificación legal. En efecto, asistimos por un lado a una arrolladora realidad dada por el avance permanente de los derechos sociales, fundamentalmente a partir de la reforma constitucional del año 1994, con la incorporación a nuestro derecho interno de los instrumentos internacionales con la misma jerarquía de la Constitución, que regula el artículo 75 inciso 22 y del principio de progresividad social que reconoce el inciso 19 de la norma, en donde se acentúa la necesidad de un progreso económico signado por la justicia social. Y de otro costado, un avance científico y tecnológico igualmente sorprendente e indetenible que se introduce en la vida cotidiana produciendo cambios irresistibles. En resumidas cuentas, la toma de conciencia de derechos por parte de los trabajadores en su conjunto, así como la irrupción de múltiples tecnologías de avanzada en todos los sectores de la actividad agraria en general, llevaban por sí a una revisión del marco legal estructural de esta actividad, que culminó con la sanción del Régimen del Trabajo Agrario por ley 26.727 y los decretos reglamentarios 300 y 301/2013.

Del análisis histórico-legal precedente, surge en forma incuestionable el convencimiento de que en la Argentina, hasta la sanción de la ley 12.789, del año 1942, denominado "estatuto de los conchabadores", y del decreto 28.169 de octubre del año 1944, aprobatorio del "estatuto del peón de campo", es decir casi al filo de la segunda mitad del siglo XX, los trabajadores rurales carecieron de instrumentos legales que fijaran condiciones mínimas de trabajo, remuneraciones, vivienda, estabilidad en el trabajo, protección contra trato discriminatorio, sindicalización, entre otras.

Como se observa, el trabajador rural ha sido constantemente, y sin una justificación valedera, tratado con cierto disvalor en su consideración legislativa.

Ello ha llevado a la Dra. Mónica Palomino Rocha a expresar que se trata de uno de los sectores más excluido históricamente tanto del mundo del trabajo como de la distribución de la riqueza de nuestro país. Más allá de ello la evolución normativa tuvo siempre por objeto mejorar sus condiciones de trabajo, aún cuando dicho avance resultó mucho más lento y gradual comparado con otros sectores productivos.

\section{La ley 26.727}

Acerca de la necesidad de una reforma del Régimen Nacional de Trabajo Agrario, ley 22.248, prácticamente todo el sector rural coincidía en su urgencia y significancia.

Sin embargo hubo dos proyectos en pugna para tan trascendental reforma. 
Uno nacido del seno sindical más representativo de los trabajadores rurales argentinos, la Unión Argentina de Trabajadores Rurales y Estibadores (UATRE) que a través de su Comisión Legislativa Rural, desarrolló un proyecto de ley que logró consensuar con las entidades de productores y el mismo se presentó ante la Honorable Cámara de Diputados de la Nación.

Desafortunadamente no corrió igual suerte cuando fue remitido al Ministerio de Trabajo de la Nación, pues pese a que el ministro Dr. Carlos Tomada asegurara su acuerdo al secretario general de UATRE, Gerónimo Venegas, luego el Poder Ejecutivo Nacional envió a Diputados otro proyecto con perceptibles diferencias, dentro de las cuales la que generó más altercados entre sindicato-gobierno fue la eliminación del Registro Nacional de Trabajadores Rurales y Empleadores (RENATRE) que era un ente de derecho público no estatal cuya administración estaba a cargo de la entidad sindical con personería gremial y la creación en su lugar del Registro Nacional de Trabajadores y Empleadores Agrarios (RENATEA) dependiente del Ministerio de Trabajo. En lo demás, ambos proyectos en lo esencial, no diferían en la tutela laboral dispensada a este colectivo.

A partir del 6 de enero de 2012 rige la ley 26.727 que establece el Régimen del Trabajador Agrario, la cual modifica parcialmente la ley 25.191 de Libreta del Trabajador Rural, deroga en forma tácita (ya que no lo dispone expresamente en ningún artículo) y en su totalidad la ley de facto 22.248 del año 1980, que había instituido el Régimen Nacional del Trabajo Agrario y con ello su decreto reglamentario 563/1981. La modificación no sólo es del título denominativo de cada uno de ellas, sino que es sustancial, generando importantes cambios en la actividad agraria.

La ley 26.727 se encuentra dividida en catorce títulos, comprendiendo un total de ciento diez artículos (a diferencia de los ciento cuarenta y siete que tenía la cerrada ley 22.248).

Resulta a todas luces una pena que la nueva normativa se haya dictado sin un merecido debate y previa consulta a la Comisión Nacional de Trabajo Agrario (C.N.T.A.) como así también a los trabajadores rurales y universidades, que seguramente hubiera permitido tener una ley diferente. Pese a ello, muchas son asimismo las virtudes de la ley 26.727 si hacemos un parangón con sus antecesoras. Caso contrario no se hubiera sancionado con un solo voto en contra en el Senado (Carlos Saúl Menen) y solo cuatro votos en contra en Diputados.

\section{La ansiada jornada de 8 horas diarias}

La ley 26.727 ha propiciado cambios relevantes en el trabajo agrario. Así, en la actualidad con dicha ley, los empleados de ese trascendental sector no se ven más privados de derechos hoy considerados fundamentales, a saber: posibilidad de negociación colectiva, posibilidad de ejercer el derecho constitucional de huelga, protección con relación a enfermedades y accidentes inculpables en caso de incapacidad definitiva (indemnización ahora no sujeta a decisión patronal), licencia por paternidad de 30 días corridos, protección contra el despido arbitrario con relación a la indemnización por omisión de preaviso e integración del mes de despido, principio de conservación del contrato de trabajo a través de la modificación de las modalidades contractuales. En lo que al presente trabajo interesa, gozan de una jornada limitada o reducida, con la consiguiente obligación del empleador de abonar como horas extras las que excedan la jornada legalmente establecida. 
También dicha ley establece la aplicación supletoria de la L.C.T. en todo lo que resulte compatible y no se oponga a la naturaleza y modalidades propias del régimen.

La derogada ley 22.248 estructuró un sistema totalmente apartado del general que regula la jornada de nuestro país a través de la ley 11.544 y que sigue la L.C.T., ya que lo hizo no sobre la base de un sistema indicativo en función de horarios como pauta de mensuración del inicio y término de la jornada, sino que utilizó el parámetro de las pausas. Es decir, prescribía descansos que debían observarse, según las exigencias impuestas por la naturaleza de la explotación y por los usos y costumbres propios de cada región. Así las cosas, la jornada laboral del trabajador rural variaba entre 12 (la mayoría de los casos) y 9 horas y media, si tenemos en cuenta el artículo 14 de la ley 22.248 que establecía como pausas para alimentación y descanso de entre dos (2) y cuatro y media ( 4 1/2) horas, según lo resolviere la Comisión Nacional de Trabajo Agrario, de acuerdo a las épocas del año y la ubicación geográfica del establecimiento y que entre la terminación de una jornada y el comienzo de la siguiente se observará una pausa ininterrumpida no menor de diez (10) horas.

Esto tuvo como directa repercusión que siempre se considerara al trabajo rural como aquél efectuado "de sol a sol", defendido en aquél entonces en virtud de que hay dos elementos que condicionan la jornada laboral en el campo: la necesidad de ejecutar tareas en determinados y distintos momentos del día, por un lado, y la influencia de los fenómenos meteorológicos, por otro. Entonces no era sostenible una jornada diaria de 8 horas, ya que quien ha tenido un mínimo contacto con el campo, no le resultará para nada extraño asumir que la jornada de trabajo se estructure de modo de conjugar las tareas a realizar con la época del año y el clima. De tal suerte que ciertas tareas sólo podrán llevarse adelante bajo ciertas condiciones climáticas, o bien, durante ciertas épocas del año. Tales circunstancias impiden condicionar la realización de ciertos trabajos a caprichosos calendarios o inclusive a definiciones legales que sólo rigen la vida social pero no los ciclos de la vida rural. Pensemos en lo surrealista que sería exigir del clima o del comportamiento animal que su evolución natural (floración, parición, enfermedad) no coincida con un día feriado, o con un horario que implica un recargo salarial.

Y como lógico corolario de la jornada de sol a sol, las horas suplementarias eran absolutamente ajenas al sistema. Es más, éstas tenían aquí otro significado, ya que al no preverse un límite diario de 8 horas y semanal de 48 horas, todas las horas laboradas se abonaban simples. Lo que se preveía era un descanso compensatorio posterior y, para el caso de incumplimiento, un castigo al empleador mediante un sistema de recargos (artículo 18 ley 22.248).

Así resolvió la Cámara de San Francisco con voto unipersonal de Mario Antonio Cerquatti en autos "Basualdo Miguel Ángel c/ Bessone Lider y otros", con fecha 5 de abril de 2013, al expresar: "Las pretendidas horas extras trabajadas al $50 \%$ y al $100 \%$ como lo consigna en su planilla, no guarda adecuación con lo dispuesto por la ley 22.248. No son computables las horas trabajadas en exceso por el trabajador agrario, tal como lo formula el actor. En este supuesto es procedente el artículo 18, inciso a), que establece que los empleadores deben abonar, junto con la remuneración el importe de medio (1/2) jornal de su categoría por cada jornada de trabajo en que no se hubieren observado las pausas. Esta cuestión está referida a los días de la semana, excluyendo el día domingo, que tiene otro tratamiento en la ley. Por lo tanto, el referido al 50\% y al 100\% resultan inadmisibles y son objeto de expreso rechazo, tal como están reclamadas". En 
sentido similar lo hizo la Cámara del Trabajo Sala 7ạ de la ciudad de Córdoba en autos "Roldán Ventura c/ Bianco Omar y otros" el 26 de marzo de 2010.

Sin embargo, antes de la reforma de la ley 26.727, hubo un intento de terminar con esta jornada prácticamente ilimitada que aquejaba a los trabajadores del agro.

La C.N.T.A. dictó la controvertida Resolución 71/08, por la cual a partir del 1 de enero del 2009 se impuso para todo el país y para todo el personal comprendido en la ley 22.248 (permanentes o no) la jornada laboral de 8 horas diarias y 48 semanales desde el día lunes hasta las 13 horas del sábado. Solo dentro de esos límites, el empleador puede proceder a la distribución de las horas de trabajo, de acuerdo con los usos y costumbres locales, dentro de los límites de su poder de dirección y organización del trabajo.

Se ha criticado seriamente esta resolución, fundamentalmente desde lo formal, es decir, en orden a las facultades legales de la C.N.T.A. para legislar en contra del texto expreso de la ley 22.248, y por ende la validez constitucional de ello.

Pavlov es tajante al advertir que la Resolución 71/08 deviene inconstitucional por resultar una flagrante modificación a una norma superior y por irrazonable en los términos del artículo 28 de la Constitución Nacional al estar reñida con el régimen que intenta reglamentar. También puede predicarse que la norma defectuosa es descalificable por haber sido sancionada por un organismo administrativo actuando en exceso de su competencia. Entonces, como puede apreciarse, esta reforma que altera en forma sustancial uno de los elementos que justifican la existencia diferenciada del régimen de trabajo rural (el llamado trabajo "de sol a sol"), debía hacerse con otra ley que provenga del Congreso de la Nación, no de la C.N.T.A.

Desde lo sustancial, la mayoría de la doctrina entendía que existía una justificación valedera para producir cambios en esta temática, la que sin duda estaba dada por factores de avance inocultables en distintos sentidos en todo lo concerniente a lo rural, sobre todo en las últimas décadas. La llegada de la electricidad a los lugares más alejados y la sorprendente irrupción de una tecnología de punta en todos los ámbitos de lo agrario daban cuenta de que ya no tenía sentido sostener que en el campo se trabajaba solamente de sol a sol.

Ya desde los considerandos en la Resolución 71/08 se destacaba que ya no resultaba justificable que no se cuenten con límites precisos para la jornada laboral por motivos propios de la faena agraria, ni tampoco se justifica que algunos trabajadores rurales gocen de jornada limitada (en virtud de las resoluciones que la C.N.T.A. había dictado limitando la jornada para ciertas actividades rurales) mientras que otros no, así como también destaca que es un hecho que muchos trabajadores rurales desarrollan tareas en exceso de jornada y ello aumenta su precarización. La limitación del horario de labor en el ámbito rural se exhibe como un progreso y mejora impostergables de las condiciones de vida de los trabajadores agrarios, viéndose con ello un impacto positivo para la creación de nuevos puestos de empleo. El gran avance tecnológico en materia agraria da a entender que no se justifica la inexistencia de una regulación similar a la que rige para otras actividades económicas ya sea industriales, comerciales o de servicios.

Teniendo en cuenta este antecedente es que la reforma establecida por la ley 
26.727 vino a imponer una jornada con base en un sistema indicativo, cambiando el molde establecido en la ley 22.248, fijando en el artículo 40 una jornada de trabajo para todo el personal agrario del país (abarcando todas las modalidades) en 8 horas diarias y 44 semanales.

Se trata de una jornada inferior a las previstas en la ley 11.544, la L.C.T. y la resolución 71/08 de la C.N.T.A., ya que en éstas la semana se fijaba en 48 horas. Es incluso inferior a la mayoría de las actividades industriales y comerciales reguladas a través de los convenios colectivos de trabajo. La distribución semanal desigual de las horas de trabajo no podrá importar el establecimiento de una jornada ordinaria diurna superior a 9 horas.

No se debe dejar de señalar que este régimen de jornada laboral resulta uno de los aspectos más controvertidos de la nueva ley, por la naturaleza, modalidades y distribución geográfica del trabajo agrario. Al producir la actividad agraria seres vivos, sujetos a las fuerzas de la naturaleza, las contingencias que pueden afectarla hacen prácticamente imposible la fijación de topes rígidos a las jornadas de trabajo rural similares a la de las actividades comerciales o industriales. En este sentido se pronuncian Maiztegui Martínez, citando caracterizada doctrina, porque la naturaleza es la que impone el ritmo al trabajo rural; y Brebbia quien puntualiza que las naturaleza y modalidades propias del trabajo rural hacen de difícil aplicación las disposiciones que rigen el trabajo industrial o comercial.

En efecto, la peculiaridad de las tareas rurales justifica un tratamiento diferenciado de la temática referida con relación al modelo industrial en el que tradicionalmente se inspiraron las reglas laborales.

Cabe notar que la nueva normativa no prevé nada sobre la pausa entre jornada y jornada, que en la ley 22.248 era de diez horas, pero que en la L.C.T. y en la Resolución 71/08 es de 12 horas. Se sostiene entonces sin vacilaciones que a fin de suplir dicha omisión son de aplicación el artículo 197 de la L.C.T. y el artículo 5 de la citada resolución, resultando entonces ser la pausa mínima e ininterrumpida entre jornada y jornada de 12 horas.

Con esta reforma, la jornada del trabajador rural argentino se encuentra entre las más protectorias de los países de la región, pasándose de una carga horaria de 72 horas semanales con la ley 22.248 a 44 horas en ese mismo período de tiempo con la ley 26.727. A continuación (Cuadro $n$ o 1) se muestra en forma sintética el derecho comprado con países limítrofes de nuestro país demostrándose con ello lo que se afirmó precedentemente

Asimismo, se trata de una novedad de la ley 26.727 la regulación sobre la jornada nocturna en su artículo 41.

La ley 22.248 no contenía disposiciones sobre jornada nocturna salvo la prohibición de ocupar en ellas trabajadores menores de 16 años (artículo 110), lo que permitía concluir que el horario laboral también podía incluir el trabajo nocturno para los demás trabajadores. 


\begin{tabular}{|c|c|c|c|c|c|}
\hline & ARGENTINA & BRASIL & PARAGUAY & URUGUAY & CHILE \\
\hline Leyes aplicables & Ley 26.727 y L.C.T. & Ley $5889 / 3$. & $\begin{array}{l}\text { Código del Trabajo, Capitulo } \\
\text { V, articulos } 157 \text { a } 192 .\end{array}$ & $\begin{array}{l}\text { Decreto Ley } 14.785 \text { y Dec. } \\
647 / 78 . \text { Reformado por ley } \\
18.441 \text { en el año } 2008 .\end{array}$ & $\begin{array}{l}\text { Código del Trabajo, } \\
\text { artículos } 87 \text { a } 95 .\end{array}$ \\
\hline Jornada & $\begin{array}{c}8 \text { horas diarias y } 44 \text { horas } \\
\text { semanales (art. } 40 \text { ley } \\
26.727) .\end{array}$ & 8 horas diarias. & $\begin{array}{l}8 \text { horas diarias y } 48 \text { horas } \\
\text { semanales. Nunca más de } 12 \\
\text { horas diarias (art. 182). }\end{array}$ & $\begin{array}{l}8 \text { horas diarias y } 48 \text { horas } \\
\text { semanales por cada } 6 \text { días } \\
\text { trabajados. }\end{array}$ & $\begin{array}{l}\text { Promedio anual que no } \\
\text { exceda las } 8 \text { horas } \\
\text { diarias, de acuerdo a las } \\
\text { caracteristicas de la zona } \\
\text { o región (art. 88). } \\
\end{array}$ \\
\hline Descansos establecidos & $\begin{array}{l}12 \text { horas entre jornadas (art. } \\
197 \text { in fine L.C.T.). }\end{array}$ & 11 horas entre jornadas. & $\begin{array}{c}\text { Descanso intermedio de } 1 \\
\text { hora y media durante la } \\
\text { jornada. }\end{array}$ & $\begin{array}{c}12 \text { horas continuas entre } \\
\text { jornadas como máximo } \\
\text { (cuando el descanso durante } \\
\text { el día sea igual o mayor a } 3 \\
\text { horas corridas), pero nunca } \\
\text { menos de } 9 \text { horas. }\end{array}$ & $\begin{array}{l}\text { Descanso diario de } \\
\text { media hora. }\end{array}$ \\
\hline Descanso semanal & $\begin{array}{l}\text { Sábados después de las } 13 \\
\text { horas y domingos. (art. } 43 \\
\text { ley 26.727). }\end{array}$ & Según las costumbres. & Domingo. & $\begin{array}{c}\text { Con preferencia en día } \\
\text { domingo, aunque las partes } \\
\text { pueden acordar que sea en } \\
\text { otro día de la semana, fijo o } \\
\text { rotativo. }\end{array}$ & Domingo. \\
\hline
\end{tabular}

Cuadro no 1

Se establece en el nuevo régimen la jornada de trabajo nocturna con las mismas características que tiene la del resto de los trabajadores de la actividad privada.

Dispone que la jornada ordinaria de trabajo integralmente nocturna no podrá exceder de 7 horas diarias ni de 42 horas semanales, entendiéndose por tal la que se cumple entre las 20 horas de un día y las 5 horas del día siguiente (en la L.C.T. es entre las 21 horas y las 6 horas del día siguiente).

También regula la jornada mixta, que al igual que lo previsto en la L.C.T., dispone que cuando se alternen horas diurnas y nocturnas se reduce proporcionalmente la jornada en 8 minutos por cada hora nocturna trabajada, debiendo abonar los 8 minutos en exceso como tiempo extraordinario.

Lo que resulta llamativo es que, como advierte Requena, pareciera habérsele pasado por alto al legislador nacional lo relativo a la jornada insalubre, desde que no se la tiene en cuenta en la ley 26.727 y no hay regulación específica en su articulado sobre este tópico, aunque la palabra insalubre aparece en reiteradas oportunidades en dicha ley.

Como es de público conocimiento la manipulación de agroquímicos y agro tóxicos es permanente en la faena rural. De todas formas será de aplicación supletoria el artículo 200 de la L.C.T., en virtud del artículo 2 inciso b) de la ley 26.727.

Con la reforma ya nadie podrá dudar de la aplicación de las horas suplementarias o complementarias al actual régimen. Por lo tanto en el artículo 42 la ley 26.727 impuso un límite a la cantidad de horas extras que puede hacer un trabajador rural estableciendo un máximo de 30 horas mensuales y 200 horas anuales, sin necesidad de autorización administrativa previa y sin perjuicio del debido respeto de las previsiones normativas relativas a jornada, pausas y descansos, tal como lo había dispuesto en su momento el decreto 484/00 y la L.C.T. 
Cabe destacar, sin embargo, que nada dice la nueva ley sobre el pago de las horas extraordinarias y las trabajadas en días sábados después de las 13 horas y los días domingos y feriados. Sin embargo, hay que tener en consideración que la expresión "horas extraordinarias" resulta homóloga a la de "horas suplementarias", mencionadas por el artículo 201 de la L.C.T. Al respecto autorizada doctrina considera que resultan aplicables los artículos 201, 205 y 207 de la L.C.T. como así también la Resolución 71/08 de la C.N.T.A.

Para finalizar con este tópico, es menester destacar que si bien se ha avanzado mucho en establecer un límite a la duración del tiempo en que el empleado rural está a disposición del empleador, todo lo relativo al control de la extensión de la jornada en la nueva ley queda sin sanción legal expresa. Resulta a todas luces una pena que con la reforma no se haya modificado el artículo 1 de la ley 11.544 de jornada que actualmente sigue teniendo una expresa exclusión a la actividad agraria. Y esta omisión legislativa produce una consecuencia práctica concreta: las previsiones que contiene el artículo 6 relativas a la obligación del empleador de llevar las planillas de horarios y descansos (incisos a y b) y en particular el inciso c que obliga a inscribirse en un registro las horas suplementarias realizadas por el trabajador, no tienen aplicación en este estatuto particular. Y siendo así, no existiendo documentación legal que en forma obligatoria deba llevar el empleador, no existe tampoco sanción a su respecto, ni como infracción administrativa ni como presunción judicial procesal.

Coincidimos con Requena que se impone por la vía legislativa la eliminación urgente en la ley 11.544 de la exclusión de la actividad agraria, a fin de que pueda aplicarse, y con ello cobren efectiva vigencia las exigencias registrales indicadas. Sólo de esta forma adquirirá completo sentido la esencial reforma que se ha introducido en este aspecto.

\section{5.- Conclusión}

Si bien es cierto que el trabajo agrario resulta, por su naturaleza, diferente del trabajo urbano o industrial, afectado el primero a estacionalidades y a los ciclos productivos del campo, prestigiosa y autorizada doctrina entendía que ello no justifica que exista una legislación tan diferenciada de la L.C.T. Muchas industrias, al igual que el trabajo agrario, tienen ciclos de producción que no pueden detenerse, valiéndose de turnos rotativos y con mayor número de personal trabajando. No se entendían, entonces, las razones que justificaban las leyes anteriores a la ley 26.727 que aquí no pueda ocurrir de igual modo.

La falta de legislación durante muchos años y luego una legislación tan contraria a los derechos del trabajador rural han contribuido a la precarización y a la explotación de la mano de obra. Desde siempre las continuas modificaciones que se han producido en materia de legislación laboral, con su carga de logros y beneficios obtenidos por el conjunto de los trabajadores argentinos no han incluido a los trabajadores del sector agropecuario, a lo que debe sumarse la altísima tasa de informalidad en materia laboral. La Resolución C.N.T.A. 71/08 ha sido celebrada por los trabajadores rurales como un gran hito en pos de la equiparación de los derechos, sin embargo la misma no superaba el test de constitucionalidad por contradecir y ser de rango inferior a la derogada ley 22.248 
Por lo tanto, con la actual ley 26.727, se debe elogiar la reducción de la jornada a este colectivo de trabajadores, ya que por las condiciones en donde se presta, se le genera un mayor impacto o desgaste a la persona que trabaja, necesitando, como corolario, un mayor tiempo de descanso para poder reponerse. Asimismo, ello ayudará a generar más puestos de empleo ya que se necesitará de más personal para cubrir las horas necesarias para poder explotar correctamente la actividad rural.

Se puede apreciar que la nueva norma ha dado con relación a la jornada de trabajo un giro de relevancia respecto de su antecesora, eliminando todo aquello que se presentaba en la ley 22.248 como peyorativamente discriminatorio. Pues bien, ahora, en la regulación del trabajo agrario, el patrón debe considerar al peón como ser humano, y éste debe realizar su labor en condiciones dignas y equitativas, con una jornada limitada, retribución justa, con poder para organizarse libre y democráticamente en la actividad sindical y así poder celebrar convenios colectivos de trabajo que regulen en forma aun más apropiada la labor de estos trabajadores.

Si bien no es cierto que el régimen dejado de lado de la ley 22.248 haya omitido considerar la persona y los derechos del trabajador rural, ni tampoco es pertinente decir que la nueva ley 26.727 sea extraordinaria o superadora de cincuenta años de trabajo denigrante en el campo argentino, consideramos que lo real e irrefutable es que hoy en día se puede afirmar que el peón de campo también es sujeto de preferente tutela, sumando hacia la igualdad y dignidad de éstos trabajadores como colectivo.

Sin lugar a dudas, la ahora jornada limitada tendrá que venir acompañada de un serio control por parte de la autoridad de aplicación, ya que seguramente, y de lo contrario, se devendrá inexorablemente en una ley justa pero no aplicable en la realidad rural de nuestro país. 


\section{Bibliografía consultada.}

- Ackerman, Mario (Director); "Estatutos y regulaciones especiales, Régimen Nacional del Trabajo Agrario" en "Tratado del Derecho del Trabajo", Tomo V (complemento), Editorial Rubinzal Culzoni, Santa Fe, 2007.

- Brebbia, Fernando, "Manual de Derecho Agrario”, Editorial Astrea, Buenos Aires, 1997.

- Capón Filas, Rodolfo; "Régimen del Trabajo Agrario Ley 26.727”, Editorial Platense, La Plata, 2012.

- Facciano, Luis A. (Director), “Nuevo Régimen del Trabajo Agrario” Ley 26.727 comentada, Editorial Nova Tesis, 2012.

- Giuliani, Marcelo; “Ley 26.727: Nuevo Régimen del Trabajo Agrario - modalidades contractuales", publicado en Rubinzal Online.

- Luparia, Carlos H.; "Régimen del trabajo rural”, Editorial Astrea, Buenos Aires, 1981.

- Maiztegui Martínez, Horacio; "El trabajador rural”, Editorial Rubinzal Culzoni, Santa Fe, 2005.

- Maiztegui Martínez, Horacio; “El nuevo estatuto del peón de campo, ley 26.727”, Ed. Rubinzal Culzoni, Santa Fe, 2012.

- Nápoli, Rodolfo; “El nuevo régimen de trabajo agrario. Ley 26.727." Revista de Derecho del Trabajo, Editorial La Ley, año LXXII, número 3, Marzo de 2012.

- Pavlov, Federico; "Trabajo rural: ahora la jornada de "sol a sol" es de 9 a 17", publicado Revista del Derecho del Trabajo, Editorial La Ley, Septiembre de 2009.

- Requena, Cristián; "Régimen de Trabajo Agrario Ley 26.727 comentada”, Editorial Alveroni, Córdoba, 2013. 